OPEN ACCESS

Edited by:

Carlo Lai,

Sapienza University of Rome, Italy

Reviewed by:

Serge Brand

University Psychiatric Clinic

Basel, Switzerland

Gianluca Serafini,

San Martino Hospital (IRCCS), Italy

*Correspondence:

Dara Mojtahed

d.mojtahedi@hud.ac.uk

Specialty section:

This article was submitted to Mood and Anxiety Disorders,

a section of the journal

Frontiers in Psychiatry

Received: 16 September 2020 Accepted: 31 December 2020

Published: 03 February 2021

Citation

Mojtahedi D, Dagnall N, Denovan A, Clough P, Hull S, Canning D, Lilley C and Papageorgiou KA (2021) The

Relationship Between Mental

Toughness, Job Loss, and Mental

Health Issues During the COVID-19

Pandemic.

Front. Psychiatry 11:607246. doi: 10.3389/fpsyt.2020.607246

\section{The Relationship Between Mental Toughness, Job Loss, and Mental Health Issues During the COVID-19 Pandemic}

\author{
Dara Mojtahedi ${ }^{1 *}$, Neil Dagnall ${ }^{2}$, Andrew Denovan ${ }^{2}$, Peter Clough ${ }^{1}$, Sophie Hull ${ }^{1}$, \\ Derry Canning $^{1}$, Caroline Lilley ${ }^{1}$ and Kostas A. Papageorgiou ${ }^{3}$
}

${ }^{1}$ Department of Psychology, Centre for Cognition and Neuroscience, University of Huddersfield, Huddersfield, United Kingdom, ${ }^{2}$ Faculty of Health, Psychology and Social Care, Manchester Metropolitan University, Manchester, United Kingdom, ${ }^{3}$ School of Psychology, Queen's University Belfast, Belfast, United Kingdom

Concerns toward public well-being and mental health are increasing considering the COVID-19 pandemic's global societal and individual impact. The present study builds on the current body of COVID-19 literature by examining the role of mental toughness (MT) in predicting negative affective states (depression, anxiety and stress) during the pandemic. The study also examined the effects of changes in employment on mental health and MT. Participants ( $N=723$ ) completed a battery of questionnaires including the Mental Toughness Questionnaire 48-item, The State-Trait Anxiety Inventory, and the Depression, Anxiety and Stress Scale - 21 items. Participants reported relatively higher levels of depression, stress and anxiety in comparison to pre-COVID-19 samples from previous research, with respondents who had lost their jobs during the pandemic reporting higher levels of negative affective states. Despite this, mentally tough individuals appeared to report lower levels of depression, anxiety and stress. Moreover, moderation analyses identified some interaction between MT and employment status when predicting depression, anxiety and stress. Our findings suggest that MT may have some utility in reducing the adverse mental health effects of the pandemic on individuals, however, further longitudinal research is needed to support these implications.

Keywords: COVID-19, mental health, mental toughness, unemployment (effects of), anxiety, depression, stress

\section{INTRODUCTION}

The COVID-19 pandemic has heightened concerns about public well-being and mental health (1). Correspondingly, there has been a rapid growth in research assessing the consequences of the coronavirus on psychological well-being. Since the effects are complex, evolving and ongoing, continuous research is required to explore the extent of the problem, and to identify potential protective factors. Acknowledging these points, the present study examined whether level of mental toughness (MT) predicted mental health outcomes during the pandemic and assessed whether high levels of MT moderated (reduced) the potential negative psychological effects of the COVID-19 pandemic. This included consideration of the consequences of occupational instability (i.e., job insecurity and loss), which research has identified as a major source of both social and individual concern [e.g., (2)]. 
Rajkumar (3), undertook a review of extant literature on COVID-19 and mental health. This revealed that symptoms of anxiety and depression (16-28\%) and self-reported stress (8\%) were common psychological reactions to the pandemic. Studies within the review noted also that stress and anxiety were frequently attendant with disturbed sleep quality $(4,5)$. Rajkumar (3) observed also that individual (e.g., mental health and age) and structural variables (e.g., support services) mediated and moderated risk. Pre-COVID literature identify further risk factors (e.g., negative affective temperaments \& pre-existing depression) that could aggravate the negative psychiatric states experienced [e.g., feelings of hopelessness and increased suicide risk, $(6,7)]$. Illustratively, due to the stress associated with the COVID-19 outbreak, patients with pre-existing mental disorders were susceptible to relapse or new episodes resulting from their disorder (8).

The general finding that self-reported anxiety, depression, and stress are common psychological reactions to the COVID-19 pandemic aligns with previous related work that has observed that psychological distress and symptoms of mental illness are associated with outbreaks of infectious disease $(9,10)$. In the context of COVID-19, resultant social and behavioral changes such as disrupted travel plans, social isolation, media information overload, and widespread panic buying of necessity goods, heightened the increasing menace of the epidemic. Collectively, these factors contributed to concern regarding the COVID-19 situation and helped to create a global atmosphere of concern and despair $(9,11)$.

An important feature of Rajkumar (3) review of COVID-19 and mental health was that it noted that individual and structural variables influenced the risk of negatives psychological consequences. In this context, a key factor is occupational security (2). Indeed, studies have noted that loss of employment and fear of unemployment are major concerns that contribute to negative affective states during the pandemic (12, 13). Relatedly, for many the pandemic has resulted in permanent or temporary (furlough) job loss, which have been previously linked with symptoms of depression (14). Despite global government attempts to relieve financial distress through increasing welfare support, Mimoun et al. (2) found that even those who were temporarily furloughed during the COVID-19 pandemic reported higher levels of distress than those who were unemployed prior to the pandemic. The authors explained that jobs "provide individuals a sense of confidence, self-esteem, and control" [(2, p. 184)].

Consideration of COVID-19-related literature supports the notion of individual differences in susceptibly to the pandemic's mental health impact. Wang et al. (15) surveyed the general public in China to better understand psychological impact (i.e., anxiety, depression, and stress) during the initial outbreak. They found that gender (i.e., female), student status, specific physical symptoms (e.g., myalgia, dizziness, coryza), and poor self-rated health status were significantly associated with greater psychological impact [i.e., higher levels of stress, anxiety, and depression as measured by the Depression Anxiety and Stress Scales, DASS21; (16)]. In a subsequent study, Wang et al. (17) conducted a longitudinal study covering the initial outbreak
(Jan 31) and the peak of the epidemic 4 weeks later. During the preliminary evaluation, moderate-to-severe stress $(8.1 \%)$, anxiety $(28.8 \%)$ and depression $(16.5 \%)$ were experienced by a noticeable minority of the group. Additionally, while the number of confirmed cases of COVID-19 increased markedly from the first to second survey, no significant changes occurred for DASS21 scores. Proposed protective factors included greater confidence in doctors, perceived survival likelihood and low risk of contracting COVID-19, satisfaction with health information, and personal precautionary measures.

From these studies it is clear that individual differences can play a significant role in mitigating the negative mental effects of the pandemic $(15,17,18)$. Although adversity and challenge are natural consequences of everyday existence, susceptibility to the adverse consequences of accompanying anxiety, depression and stress can prove detrimental to mental health, well-being and everyday functioning (i.e., social, educational, occupational functioning \& suicide ideation) $(6,19)$. Thus, with regards to the COVID-19 pandemic, it is important to identify and understand psychological factors that protect against potential commensurate anxiety, depression and stress. One widely researched positive psychological construct that has been associated with beneficial outcomes across a range of settings (e.g., educational, occupational and sport) is mental toughness (MT).

The concept of MT is highly relevant to the COVID-19 pandemic because it provides a conceptual framework for understanding individual differences in resilience and reactivity to negative impacts. At a general level, MT serves as an umbrella term to denote enabling psychological resources across a range of achievement contexts that promote positive mental health (2022). The concept was initially employed within the domain of sport psychology to denote a battery of experientially developed and heritable psychological resources (i.e., values, attitudes, emotions, cognitions, and behaviors) that facilitated success in sports and physical activity (23). However, since its emergence, MT has been employed within clinical, developmental and occupational contexts, demonstrating similar enabling effects on achievement and positive mental health (24-32).

There are various conceptualisations of MT [e.g., $(33,34)]$. The most widely cited and generally applied model was proposed by Clough and colleagues. Clough et al. (35) characterized MT as a composite of four interrelated, but independent components: [1] Control (life and emotion): the tendency to feel and act as if one is influential and keep anxieties in check; [2] Commitment: the tendency to be deeply involved in pursuing goals despite difficulties that arise; [3] Challenge: the tendency to see potential threats as opportunities for self-development and to continue to strive in changing environments; and [4] Confidence (in abilities and interpersonal): the belief that one is a truly worthwhile person in spite of setbacks, and the ability to push oneself forward in social settings.

Commensurate with previous work, the authors postulated that high levels of MT would attenuate the adverse psychological effects of the COVID-19 pandemic. This rationale derived from innumerable studies evidencing that individuals with higher levels of MT adapt better to stressful situations (36-38). 
For example, in a longitudinal study, Gerber et al. (37) explored the relationships between MT, psychological stress, depressive symptoms, and life satisfaction. Both perceived stress and depressive symptoms correlated negatively with MT. Moreover, MT was positively associated with life satisfaction. The researchers also found that well-adjusted individuals (low levels of stress, few depressive symptoms, and high life satisfaction) scored high on MT, whereas maladjusted individuals (high levels of stress, depressive symptoms, and little life satisfaction) tended to have lower levels of MT. Interestingly, resilient (moderate levels of stress at baseline, decreased depressive symptoms and increased life satisfaction at follow-up) and deteriorated (increasing levels of stress, increasing depressive symptoms, and decreasing life satisfaction) individuals did not differ at baseline but showed an increase/decline of MT over time (resilient and deteriorating individuals, respectively).

Consistent with these findings, Gerber et al. (37) showed that MT was associated with lower perceived stress and fewer depressive symptoms in a sample of 284 high school students and in a sample of 140 undergraduate students. They also showed that MT moderates the relationship between high perceived stress and depressive symptoms. More specifically, high levels of MT were associated with lower depressive symptoms, when perceived stress levels were high.

\section{Present Study}

Research on the mental health implications of the COVID19 pandemic is rapidly growing. However, relatively little academic work has attempted to identify dispositional protective factors against negative affective state during the pandemic (39). Previous research has identified a clear link between MT and resilience to stress, however, prior to this paper the relationship had not be explored in the context of the COVID-19 pandemic - a period of global and societal distress. Accordingly, the present study examined the relationship between MT and self-reported levels of depression, anxiety, and stress. Past research suggests that mentally tough individuals are less prone to experiencing negative emotions when placed in stressful situations $(37,38)$. Emanating from this, the current authors contend that mentally tough individuals should therefore be less susceptible to negative affective states during lockdown. More specifically, three hypotheses have been formulated: Hypothesis one predicts that MT traits will be negatively correlated with depression (DASS21); Hypothesis two predicts that MT traits will be negatively correlated with anxiety (DASS21 \& STAI-Y1); and Hypothesis three predicts that MT traits will be negatively correlated with stress (DASS21).

Clough et al. (35) define MT as a stable, narrow, personality trait. This supposition is supported by consistent evidence of a genetic underpinning [e.g., (40-42)]. However, they recognize also that MT is modified by environmental factors, [e.g., training, (43); and positive youth experiences (44)]. Thus, it is possible that sustained and pervasive stressors may affect toughness scores. One objective stressor is job loss. Losing one's job often has a negative effect on well-being (14). Uniquely, in the current pandemic there are four options: retaining the job, furlough, job loss and previously unemployed. Thus, the second aim of the study was to examine whether employment status had an effect on MT scores and negative affective state. Due to a lack of research exploring the stability of MT, no predictions were made on the relationship between employment status and MT. However, the effects of job loss on mental health have been observed within past research $[$ see $(2,14)]$. Based on these findings, the following additional hypotheses are presented: Hypothesis four predicts that respondents who had lost their jobs during the pandemic will report higher level depression (DASS21) than those in employment; Hypothesis five predicts that respondents who had lost their jobs during the pandemic will report higher level anxiety (DASS21 \& STAI-Y1) than those in employment; and Hypothesis six predicts that respondents who had lost their jobs during the pandemic will report higher levels of stress (DASS21) than those in employment.

The present study is the first to examine the role of MT during the COVID-19 pandemic and does so using a large diverse sample (internationally and temporally, see below) to produce representative results. The research will allow us to determine whether such traits can mitigate mental health problems during the pandemic. Moreover, the practical implications of the findings can inform future strategies for protecting public mental health during current and future pandemics.

\section{MATERIALS AND METHODS}

\section{Samples and Design}

This study was cross-sectional in nature. The cross-sectional approach is frequently criticized because it is inclined to common method variance (CMV) (45). This occurs when variations in responses reflect measurement procedure rather than underlying differences in the observed construct(s). To counter CMV, the researchers employed procedural remedies (46). Firstly, instructions created psychological distance between scales by emphasizing that each measure assessed a separate construct. Encouraging respondents to perceive scales as distinct has previously successfully reduced common method variance (47). Secondly, the instructions attempted to negate social desirability effects and evaluation apprehension by stating that there were no correct answers. Published studies have previously successfully implemented these procedural remedies [e.g., $(48,49)]$.

The study used self-report measures hosted online via Qualtrics. Data collection occurred at two different time-points on independent samples to determine whether the association between MT and negative states could be replicated. The inclusion criteria required all participants to be aged 18 or above and speak English proficiently. The combined dataset consisted of 723 participants (male $=315$, female $=407$, and other $=$ $1)$, aged between 18 and $78(M=35.06, S D=13.65)$. The demographic details of both samples are presented in Table 1. The first sample (Sample A) consisted of 376 participants (male $=95$, female $=280$, other $=1)$ aged between 18 and $78(M=$ $34.10, S D=14.34)$ from the UK and Ireland. Data collection was carried out between April 23rd and May 21st, with most responses (76.33\%) collected between April 23rd and April 30th, 2020. The survey was advertised through social media and online 
TABLE 1 | Demographic variables for samples.

\begin{tabular}{lccc}
\hline & $\begin{array}{c}\text { Sample A } \\
(\boldsymbol{n}=\mathbf{3 7 6})\end{array}$ & $\begin{array}{c}\text { Sample B } \\
(\boldsymbol{n}=\mathbf{3 4 7})\end{array}$ & $\begin{array}{c}\text { Total } \\
(\mathbf{N}=\mathbf{7 2 3})\end{array}$ \\
\hline $\begin{array}{l}\text { Age }(M, s d) \\
\text { Gender }\end{array}$ & $34.1(14.34)$ & $36.09(12.79)$ & $35.06(13.65)$ \\
$\quad$ Male & $95(25.3 \%)$ & $220(63.4 \%)$ & $315(43.6 \%)$ \\
Female & $280(74.5 \%)$ & $127(36.6 \%)$ & $407(56.3 \%)$ \\
Other & $1(0.3 \%)$ & 0 & $1(0.1 \%)$ \\
Employment & & & \\
Job loss & $14(3.9 \%)$ & $50(14.4 \%)$ & $64(9.1 \%)$ \\
Furloughed & $75(21 \%)$ & $31(8.9 \%)$ & $106(15.1 \%)$ \\
Previously unemployed & $63(17.6)$ & $46(13.3 \%)$ & $109(15.5 \%)$ \\
$\quad$ Working (traveling) & $80(22.4 \%)$ & $66(19 \%)$ & $146(20.7 \%)$ \\
$\quad$ Working (home) & $125(35 \%)$ & $154(44 \%)$ & $279(36.9 \%)$ \\
\hline
\end{tabular}

internet groups. Participants from Sample A were not financially compensated for their involvement.

Data for the second sample (Sample B) were collected on May 18th and May 25th, 2020, with the majority (97.4\%) of responses collected on May 25th. For Sample B, the authors recruited participants via an online crowd sourcing marketplace, Amazon Mechanical Turk (Mturk). Each respondent was rewarded \$0.30 for their involvement. Previous research indicates that data collected through Mturk are of high quality (50). Additionally, measures were taken to ensure that respondents were reading and responding to the questions logically (as opposed to haphazardly providing responses to receive the reward).

Three validity-test questions were placed within the survey instructing participants to select a specific response (e.g., "for this question please select the number 4"). In total 415 participants were recruited. However, 68 cases were omitted from the study after failing to correctly answer the validity-test questions, leaving a final sample of 347 participants $($ male $=220$, female $=127$ ) aged between 18 and $76(M=36.09, S D=12.79)$. In order to allow for cultural comparisons to be made between the two samples, the authors used Mturk's preference filter to make the Sample B survey only available to non-UK participants, however, 17 participants from the UK still managed to complete the survey and were included in the final sample. The other participants from Sample B were from North America $(n=239)$, India $(n=$ $60)$, and Brazil $(n=18)$ and other $(n=13)$.

The survey asked questions pertaining to the participants' (i) demographic information (including job status), (ii) negative affective states during the pandemic (i.e., anxiety, depression, and stress), and (iii) mental toughness. The survey also contained some additional questions about the participants' general wellbeing and attitudes toward COVID-19, however these items were not of interest to the present study and thus, they are not discussed further. The average completion time was $21 \mathrm{~min}$ for respondents in Sample A and $15 \mathrm{~min}$ for respondents in Sample B.

\section{Measures}

Respondents provided information about their age, gender, country of residence and job status during the pandemic. For job status, participants were asked to select the most appropriate response from the following options: Unemployed before the pandemic, I lost my job/business during the pandemic, furloughed, I still have my job/business and travel to work, I still have my job/business and working from home (WFH).

Depression, Anxiety, and Stress Scale [DASS21; (51)] is a 21-item self-report instrument that measures symptoms of depression, anxiety and stress at the time of participation. Each item is presented as a statement that the participant rates their agreement to using a four-point Likert scale $(0=$ Did not apply to me at all, $3=$ Applied to me very much or most of the time). The scores for each subscale are calculated by multiplying the sum of the respective items by two. DASS21 was identified as a suitable measure for the present study due to demonstrating high internal consistency across clinical and non-clinical samples (5254). High Cronbach's alphas were observed within the present study for Sample A (Stress $=0.9$, Anxiety $=0.82$, Depression $=0.91)$ and $\mathrm{B}$ (Stress $=0.91$, Anxiety $=0.92$, and Depression $=0.92$ ).

Spielberger State-Trait Anxiety Inventory [STAI; (55)] measures trait (baseline) and state (situational) anxiety, through two 20 -item scales. The items describe different affective states and participants are required to indicate how much each statement reflects their mood either at the time of survey completion (STAI-Y1) or in general (STAI-Y2) using a fourpoint Likert scale $(1=$ almost never/not at all, $4=$ almost always/very much so). Research studies [e.g., (56, 57)] have continuously supported the construct validity of both subscales. High Cronbach's alphas were also observed within the present study within Sample A (STAI-Y1 = 0.96; STAI-Y2 = 0.94) and B (STAI-Y1 $=0.91$; STAI-Y2 $=0.92$ ).

The Mental Toughness Questionnaire 48 [MTQ48; (35)] measures MT through four components: Control (14 items), Confidence (15 items), Commitment (11 items) and Challenge (8 items). Participants are required to indicate their level of agreement using a five-point Likert scale ( $1=$ strongly disagree; $5=$ strongly agree). Each component is scored by calculating the mean of the respective items with higher scores indicating a greater level of MT. The MTQ-48 has established internal and test-retest reliability $(36,37,40,58,59)$. Furthermore, Clough et al. (35) provide evidence for MTQ-48 construct validity via significant relationships with related measures (i.e., optimism, self-image, satisfaction with life, self-efficacy, and trait anxiety). High Cronbach's alphas were also observed within the present study within Sample A (Challenge $=0.82$; Commitment $=0.86$; Control $=0.77$; and Confidence $=0.88)$ and $\mathrm{B}$ (Challenge $=0.67$; Commitment $=0.79 ;$ Control $=0.68$; and Confidence $=0.78$ ).

\section{Statistical Analysis}

All statistical analyses were performed using SPSS ${ }^{\circledR} 26.0$ (IBM Corporation, Armonk NY, USA) for Windows ${ }^{\circledR} /$ Apple Mac ${ }^{\circledR}$. For all regression models, preliminary analyses were conducted to ensure no violation of the assumptions of linearity, and homoscedasticity. The collinearity statistics (VIF \& Tolerance) for all models indicated that multicollinearity was unlikely to be a problem [see (60)]. All predictor variables were statistically correlated with the outcome variables which indicates that the 
TABLE 2 | Scale averages.

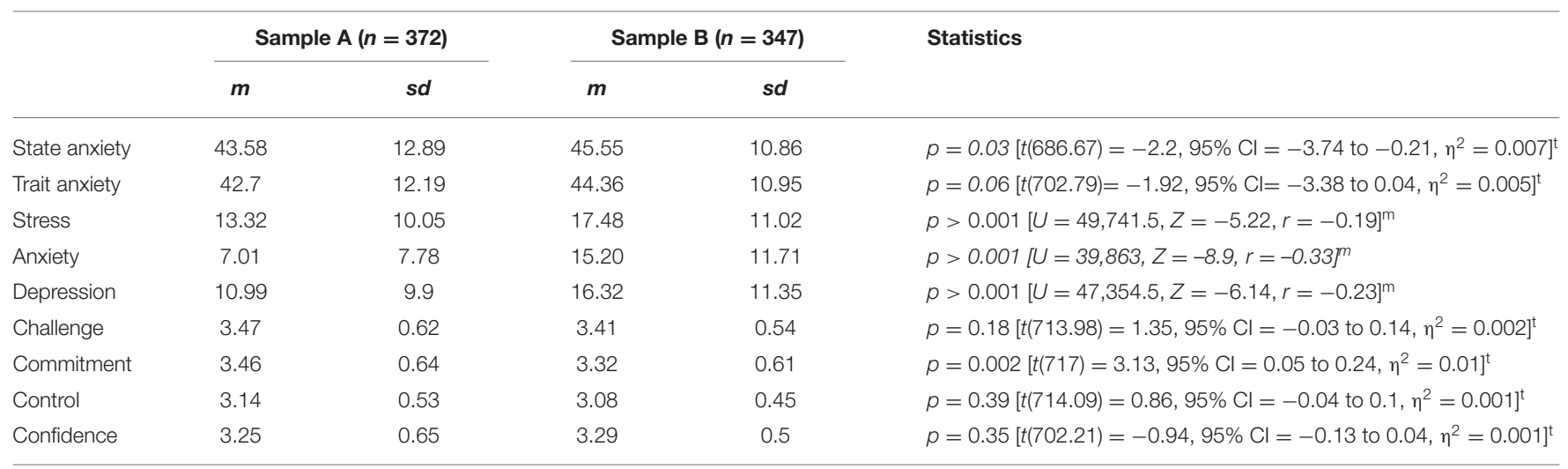

corrected alpha $=0.005{ }^{t}{ }^{t}=t$-test (two-tailed), ${ }^{m}=$ Mann-Whitney $U$.

TABLE 3 | Correlations between continuous variables.

\begin{tabular}{|c|c|c|c|c|c|c|c|c|c|c|c|c|c|c|c|c|c|c|}
\hline & \multicolumn{9}{|c|}{ Sample A } & \multicolumn{9}{|c|}{ Sample B } \\
\hline 2.Trait anxiety & & 1 & 0.64 & 0.63 & 0.71 & -0.6 & -0.62 & -0.74 & -0.77 & & 1 & 0.75 & 0.64 & 0.77 & -0.57 & -0.73 & -0.77 & -0.74 \\
\hline 3. Stress (dass) & & & 1 & 0.72 & 0.72 & -0.4 & -0.4 & -0.55 & -0.48 & & & 1 & 0.87 & 0.89 & -0.31 & -0.63 & -0.62 & -0.49 \\
\hline 4. Anxiety (Dass) & & & & 1 & 0.68 & -0.44 & -0.42 & -0.56 & -0.51 & & & & 1 & 0.85 & -0.25 & -0.59 & -0.57 & -0.4 \\
\hline 6.Challenge (MT) & & & & & & 1 & 0.63 & 0.67 & 0.7 & & & & & & 1 & 0.61 & 0.61 & 0.72 \\
\hline 7.Commitment (MT) & & & & & & & 1 & 0.66 & 0.67 & & & & & & & 1 & 0.76 & 0.74 \\
\hline 8.Control (MT) & & & & & & & & 1 & 0.77 & & & & & & & & 1 & 0.76 \\
\hline 9.Confidence (MT) & & & & & & & & & 1 & & & & & & & & & 1 \\
\hline
\end{tabular}

All relationships were statistically significant $(p<0.001)$.

data was suitably correlated with the dependent variables for examination through multiple linear regression to be reliably undertaken. All measures of effect size were interpreted in accordance with Cohen (61).

\section{RESULTS}

\section{Depression, Anxiety, and Stress During the COVID-19 Pandemic}

Preliminary observations were conducted to test the normality assumptions of the dependent variables. Observations of the histograms indicated that the DASS21 variables (depression, anxiety, and stress) were not normally distributed. As a result, between-group comparisons of DASS21 scores were conducted using non-parametric tests. Following this, a series of $t$-tests and Mann-Whitney $U$-tests were conducted to compare the two samples in mental toughness and affective states (see Table 2). Bonferroni corrections were applied (corrected to $p=005$ ).

There were no significant differences between the two samples in state anxiety and trait anxiety at the corrected alpha. In relation to the DASS21 variables (depression, anxiety, and stress), preliminary observations indicated that the data was not normally distributed, therefore Mann-Whitney U tests were used to compare the samples. For stress, $27.5 \%$ of Sample A reported moderate to extremely severe levels of stress compared to $47.8 \%$ of Sample B [see (51) for label scoring]. Differences in stress scores were found to be statistically significant, but small. For anxiety, $31 \%$ of Sample A reported moderate to extremely severe levels of anxiety compared to $63.7 \%$ of Sample B. Differences in anxiety scores were also significant, but small. For depression, $33.1 \%$ of Sample A reported moderate to extremely severe levels of depression compared to $62.6 \%$ of Sample B. Differences in depression scores were also significant, but small. In relation to MT, differences in Commitment reached statistical significance, however, the eta squared statistic indicated a small effect size (see Table 2). No significant differences were found for Challenge, Control, and Confidence.

\section{Mental Toughness and Negative Affective States}

A series of hierarchical multiple regressions (HMR) were performed to investigate the ability of MT traits (Challenge, Commitment, Control, \& Confidence) to predict depression, anxiety and stress. To reduce the effects of individual differences 
in baseline negative affectivity, a hierarchical model was used to control for trait anxiety (STAI-Y2). In the first step of HMR, four predictors were entered: Challenge, Commitment, Control, \& Confidence; the second step then introduced trait anxiety to the model. Due to the sample comparisons identifying significant differences in depression, anxiety and stress, the association between MT traits and negative affective states were assessed for each sample individually. The correlations between all continuous variables are presented in Table 3. The table suggests that the correlations between the variables were relatively similar across both samples. The correlations between MT traits and negative affective states were small to large $(r=-0.31$ to -0.77). All predictor variables were statistically correlated with depression, anxiety (DASS21 and STAI-Y1) and stress, which indicates that the data was suitably correlated with the dependent variables for examination through multiple linear regression. The HMR model properties for Sample A and B are presented in Tables 4, 5, respectively.

\section{Stress}

A HMR model was used to predict stress within Sample A. In the first step of hierarchical multiple regression, the model was statistically significant $F_{(4,350)}=39.6 ; p<0.001$ and explained $31.2 \%$ of variance in state stress. Control made a significant unique contribution to the model (see Table 4). After entry of trait anxiety at Step 2 the total variance explained by the model as a whole was $42.1 \%\left[F_{(5,349)}=52.57 ; p<0.001\right]$. The introduction of trait anxiety explained an additional $11.8 \%$ of variance in state stress, after controlling for the mental toughness traits $\left[F_{(1,349)}\right.$ $=72.2 ; p<0.001]$. In the final adjusted model, trait anxiety and Control were statistically significant.

For Sample B, in the first step, the model was statistically significant $F_{(4,342)}=76.53 ; p<0.001$ and explained $47.2 \%$ of variance in state stress. Three predictors made a significant unique contribution to the model (see Table 5). After entry of trait anxiety at Step 2 the total variance explained by the model as a whole was $62.7 \%\left[F_{(5,341)}=114.64 ; p<0.001\right]$. The introduction of trait anxiety explained an additional $15.5 \%$ of variance in state stress, after controlling for the mental toughness traits $\left[F_{(1,341)}=141.4 ; p<0.001\right]$. In the final adjusted model, all five predictor variables were statistically significant.

\section{Depression}

A HMR was next used to predict depression within Sample A. In the first step, the model was statistically significant $F_{(4,351)}$ $=60.53 ; p<0.001$ and explained $41 \%$ of variance in state depression. Three of the four mental toughness traits made a significant unique contribution to the model (see Table 4). After entry of trait anxiety at Step 2 the total variance explained by the model as a whole was $52 \%\left[F_{(5,350)}=60.46 ; p<0.001\right]$. The introduction of trait anxiety explained an additional $11 \%$ of variance in state depression, after controlling for the mental toughness traits $\left[F_{(1,350)}=77.89 ; p<0.001\right]$. In the final adjusted model, trait anxiety and Confidence were statistically significant.

For Sample B, in the first step, the model was statistically significant $F_{(4,342)}=105.41 ; p<0.001$ and explained $55.2 \%$ of variance in state depression. Three of the four mental toughness

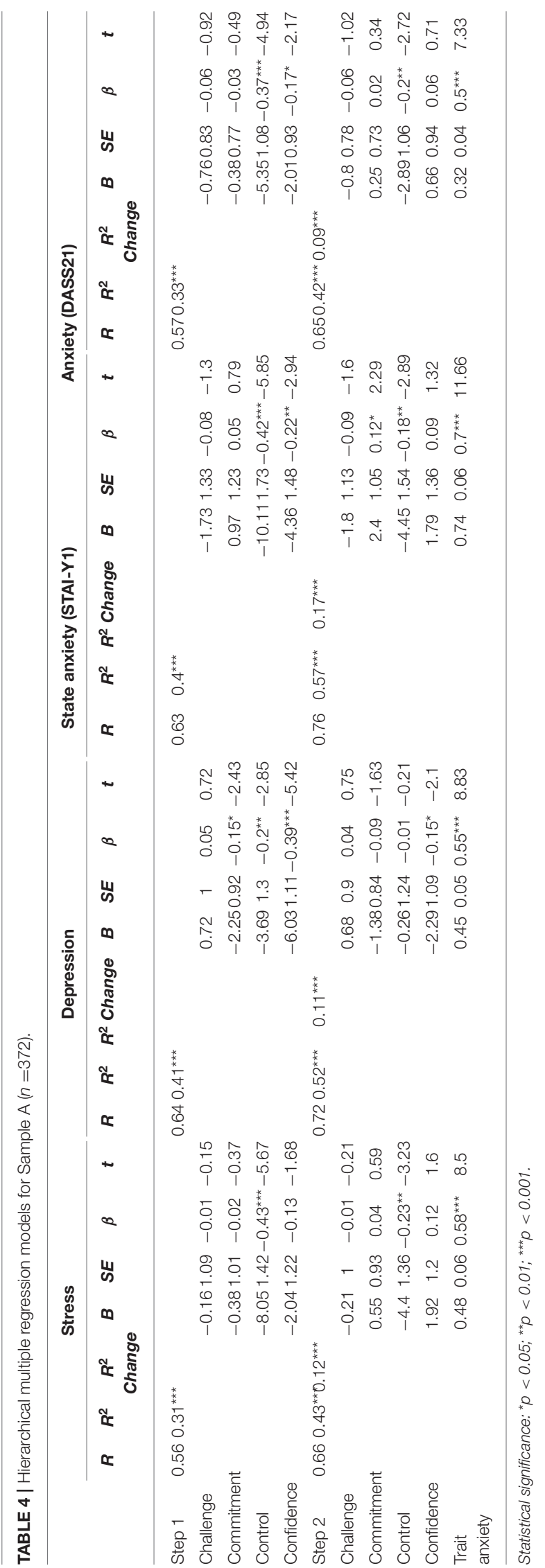




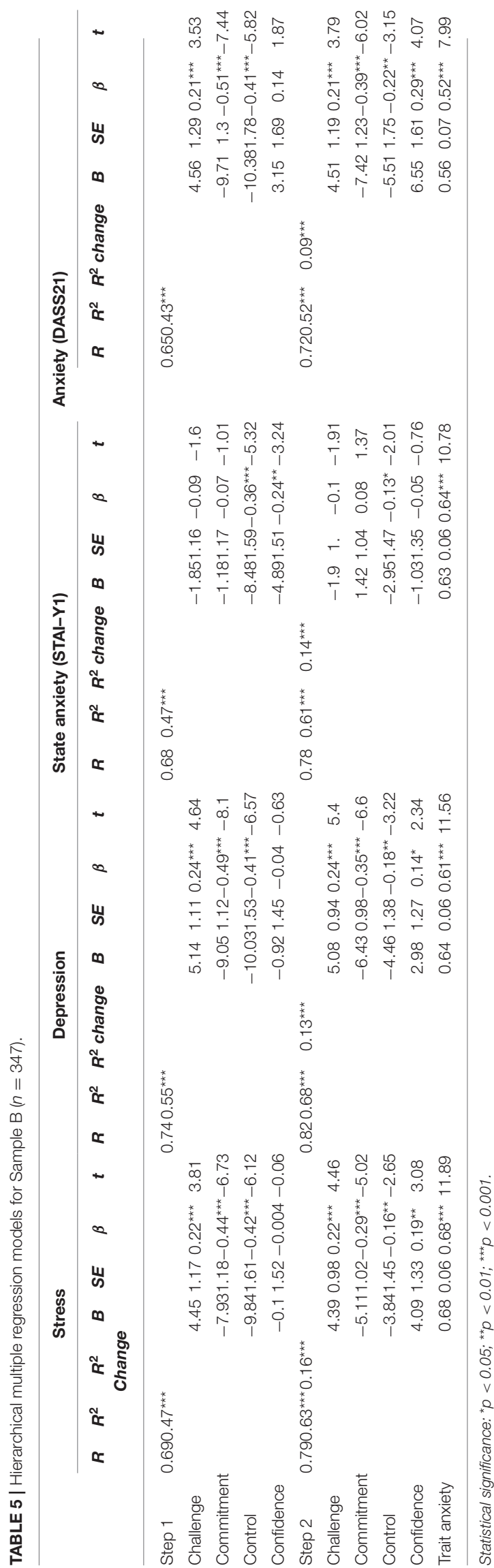

traits made a significant unique contribution to the model (see Table 5). After entry of trait anxiety at Step 2 the total variance explained by the model as a whole was $67.8 \%\left[F_{(5,341)}=143.71\right.$; $p<0.001]$. The introduction of trait anxiety explained an additional $12.6 \%$ of variance in state depression, after controlling for the mental toughness traits $\left[F_{(1,341)}=133.52 ; p<0.001\right]$. In the final adjusted model, all five predictor variables were statistically significant.

\section{State Anxiety (STAI-Y1)}

A HMR was next used to predict state anxiety (STAI-Y1) within Sample A. In the first step, the model was statistically significant $F_{(4,339)}=56.06 ; p<0.001$ and explained $40 \%$ of variance in state anxiety. Two of the four mental toughness traits made a significant unique contribution to the model (see Table 4). After entry of trait anxiety at Step 2 the total variance explained by the model as a whole was $57 \%\left[F_{(5,338)}=89.89 ; p<0.001\right]$. The introduction of trait anxiety explained an additional $17.3 \%$ of variance in state anxiety, after controlling for the mental toughness traits $\left[F_{(1,338)}=135.96 ; p<0.001\right]$. In the final adjusted model, trait anxiety, Control and Commitment were statistically significant.

For Sample B, in the first step, the model was statistically significant $F_{(4,342)}=75.12 ; p<0.001$ and explained $46.8 \%$ of variance in state anxiety. Two of the four mental toughness traits made a significant unique contribution to the model (see Table 5). After entry of trait anxiety at Step 2 the total variance explained by the model as a whole was $60.3 \%\left[F_{(5,341)}=103.58\right.$; $p<0.001]$. The introduction of trait anxiety explained an additional $13.5 \%$ of variance in state anxiety, after controlling for the mental toughness traits $\left[F_{(1,341)}=116.21 ; p<0.001\right]$. In the final adjusted model, trait anxiety and Control were statistically significant.

\section{Anxiety (DASS21)}

A HMR was next used to predict anxiety (DASS21) within Sample A. In the first step, the model was statistically significant $F_{(4,351)}$ $=43.04 ; p<0.001$ and explained $33 \%$ of variance in anxiety (DASS21). Two of the four mental toughness traits made a significant unique contribution to the model (see Table 4). After entry of trait anxiety at Step 2 the total variance explained by the model as a whole was $42 \%\left[F_{(5,338)}=89.89 ; p<0.001\right]$. The introduction of trait anxiety explained an additional $8.9 \%$ of variance in anxiety (DASS21), after controlling for the mental toughness traits $\left[F_{(1,350)}=53.78 ; p<0.001\right]$. In the final adjusted model, trait anxiety and Control were statistically significant.

For Sample B, in the first step, the model was statistically significant $F_{(4,342)}=63.76 ; p<0.001$ and explained $42.7 \%$ of variance in anxiety (DASS21). Three of the four mental toughness traits made a significant unique contribution to the model (see Table 5). After entry of trait anxiety at Step 2 the total variance explained by the model as a whole was $51.7 \%\left[F_{(5,341)}=73.14\right.$; $p<0.001]$. The introduction of trait anxiety explained an additional $9 \%$ of variance in anxiety (DASS21), after controlling for the mental toughness traits $\left[F_{(1,341)}=63.82 ; p<0.001\right]$. In the final adjusted model, all five predictor variables were statistically significant. 
TABLE 6 | MT scores for job outcome group.

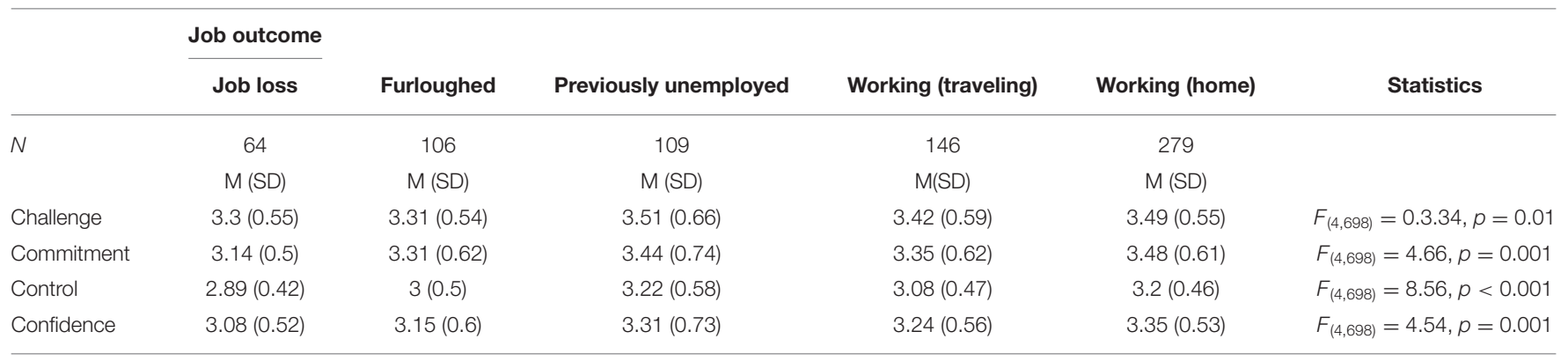

\section{Employment Status as a Predictor of Mental Toughness and Affective State}

As illustrated in the Table 1, there were some proportional differences in employment status between the samples. Most notably, very few participants from Sample A had lost their job/business during the pandemic, in comparison to Sample B. To ensure that all employment status groups had a sufficient number of cases for reliable comparisons to be made, data from the two samples were combined for the subsequent analyses.

\section{Employment Status and Mental Toughness}

A between-groups multivariate analysis of variance was conducted to explore the impact of employment status on MT traits (Challenge, Commitment, Control, \& Confidence). Descriptive and inferential statistics for MT differences between employment status groups are presented in Table 6. There was a statistically significant main effect for employment, $\left[F_{(16,2123.9)}\right.$ $=2.56, p=0.001$; Wilks' $\Lambda=0.94]$. Univariate comparisons found a significant main effect for job outcome on all MT traits, inferential statistics are presented in Table 6. Further post-hoc Tukey comparisons are presented in Table 7 and discussed below.

Post-hoc comparisons for Challenge scores indicated that the mean score for furloughed participants was significantly lower than WFH participants; the difference between the groups was small. For Commitment scores, post-hoc tests indicated that the mean score for Commitment in job/business loss participants was significantly lower than WFH participants and previously unemployed participants; these differences were moderate and small, respectively. In relation to Control scores, post-hoc tests indicated that the mean score for job/business loss participants was significantly lower than WFH participants and previously unemployed participants. Both differences were moderate. Additionally, the mean score for Control in furloughed participants was significantly lower than WFH participants and previously unemployed participants. The differences here were small. Finally, for Confidence, posthoc comparisons indicated that the mean score for WFH participants was significantly higher than furloughed participants and job/business loss participants. The differences were small and moderate, respectively.
TABLE 7 | Significant post-hoc comparisons for job outcome and MT.

\begin{tabular}{|c|c|c|c|}
\hline & Statistics & & \\
\hline & $p$ & $95 \% \mathrm{Cl}$ & $d$ \\
\hline \multicolumn{4}{|l|}{ Challenge } \\
\hline Furloughed $<$ WFH & 0.05 & -0.36 to -0.001 & 0.33 \\
\hline \multicolumn{4}{|l|}{ Commitment } \\
\hline Job loss $<$ WFH & 0.001 & -0.57 to -0.1 & 0.57 \\
\hline $\begin{array}{l}\text { Job loss < previously } \\
\text { unemployed }\end{array}$ & 0.02 & -0.57 to -0.03 & 0.44 \\
\hline \multicolumn{4}{|l|}{ Control } \\
\hline Job loss < WFH & $<0.001$ & -0.5 to -0.13 & 0.69 \\
\hline $\begin{array}{l}\text { Job loss }<\text { previously } \\
\text { unemployed }\end{array}$ & $<0.001$ & -0.54 to -0.13 & 0.63 \\
\hline Furloughed < WFH & 0.004 & -35 to -0.04 & 0.42 \\
\hline $\begin{array}{l}\text { Furloughed < previously } \\
\text { unemployed }\end{array}$ & 0.01 & -0.4 to -0.04 & 0.41 \\
\hline \multicolumn{4}{|l|}{ Confidence } \\
\hline Job loss $<$ WFH & 0.01 & 0.05 to 0.5 & 0.51 \\
\hline Furloughed $<$ WFH & 0.02 & 0.02 to 0.39 & 0.36 \\
\hline
\end{tabular}

\section{Employment Status and Negative Affective State}

Lastly, four moderation analyses were carried out using hierarchical regressions to determine whether MT traits moderated the effects of different job outcomes on negative affective states (state anxiety, DASS21 anxiety, depression and stress). A dummy coding procedure was used to test the predictive abilities of each individual job outcome, with WFH as the reference category. The moderator variables (Challenge, Commitment, Control, \& Confidence) were centered to allow the effect of the predictor to be distinguishable from the interaction. For each regression, the first step included the predictor (job outcome) and centered moderator variables (Challenge, Commitment, Control, \& Confidence) and the second step introduced the interactions between these variables. The inferential properties for all four models are parented in Table 8.

The final model for state anxiety (STAI-Y1) was statistically significant $\left[F_{(24,676)}=22.99 ; p<0.001\right]$ and explained $44.9 \%$ of variance. Job loss, Challenge, Control and Confidence made 
TABLE 8 | Hierarchical multiple regressions for emotional states.

\begin{tabular}{|c|c|c|c|c|c|c|c|c|c|c|c|c|c|c|c|c|c|c|c|c|c|c|c|c|}
\hline & \multicolumn{6}{|c|}{ SA } & \multicolumn{6}{|c|}{ Depression } & \multicolumn{6}{|c|}{ Anxiety } & \multicolumn{6}{|c|}{ Stress } \\
\hline & $R$ & $R^{2}$ & $B$ & $S E$ & $\beta$ & $t$ & $R$ & $R^{2}$ & $B$ & $S E$ & $\beta$ & $t$ & $R$ & $R^{2}$ & $B$ & $S E$ & $\beta$ & $t$ & $R$ & $R^{2}$ & $B$ & $S E$ & $\beta$ & $t$ \\
\hline Step 1 & 0.66 & 0.43 & & & & & 0.68 & 0.46 & & & & & 0.69 & 0.34 & & & & & 0.62 & 0.38 & & & & \\
\hline Job loss & & & 3.6 & 1.29 & $0.09^{\star \star}$ & 2.79 & & & 4.49 & 1.14 & $0.12^{\star \star \star}$ & 3.92 & & & 4.68 & 1.23 & $0.13^{\star \star \star}$ & 3.81 & & & 3.59 & 1.2 & $0.1^{\star *}$ & 3.01 \\
\hline Furloughed & & & -0.02 & 1.05 & -0.001 & -0.02 & & & -0.31 & 0.93 & -0.01 & -0.34 & & & -0.88 & 1. & -0.03 & -0.87 & & & -1.33 & 0.97 & -0.04 & -1.36 \\
\hline Working (t) & & & 0.6 & 0.94 & 0.02 & 0.64 & & & 0.1 & 0.83 & 0.004 & 0.12 & & & 1.81 & 0.89 & $0.07^{*}$ & 2.03 & & & 1.59 & 0.87 & 0.06 & 1.84 \\
\hline P.Unemployed & & & -0.65 & 1.03 & -0.02 & -0.63 & & & -1.52 & 0.92 & -0.05 & -1.66 & & & -1.63 & 0.99 & -0.05 & -1.65 & & & -1.56 & 0.96 & -0.05 & -1.63 \\
\hline Challenge & & & -1.93 & 0.88 & $-0.09^{\star}$ & -2.2 & & & 2.75 & 0.78 & $0.15^{\star \star \star}$ & 3.54 & & & 1.45 & 0.83 & 0.08 & 1.74 & & & 1.85 & 0.81 & $0.1^{*}$ & 2.28 \\
\hline Commitment & & & -0.22 & 0.82 & -0.01 & -0.27 & & & -6.27 & 0.73 & $-0.36^{\star \star \star}$ & -8.59 & & & -5.9 & 0.78 & $-0.35^{\star \star \star}$ & -7.52 & & & -4.34 & 0.76 & $-0.26^{\star \star \star}$ & -5.7 \\
\hline Control & & & -9.15 & 1.17 & $-0.38^{\star \star \star}$ & -7.8 & & & -6.58 & 1.04 & $-0.3^{\star \star \star}$ & -6.34 & & & -7.83 & 1.12 & $-0.37^{\star \star \star}$ & -7.01 & & & -9.12 & 1.09 & $-0.43^{\star \star \star}$ & -8.4 \\
\hline Confidence & & & -4.23 & 1.03 & $-0.21^{\star \star \star}$ & -4.12 & & & -2.87 & 0.91 & $-0.15^{\star \star}$ & -3.15 & & & 1.75 & 0.98 & 0.1 & 1.79 & & & -0.42 & 0.95 & -0.02 & -0.44 \\
\hline Step 2 & 0.67 & 0.45 & & & & & 0.69 & 0.47 & & & & & 0.61 & 0.37 & & & & & 0.64 & 0.41 & & & & \\
\hline Job loss & & & 4.23 & 1.49 & $0.1^{\star \star}$ & 2.85 & & & 4.22 & 1.32 & $0.11^{\star \star}$ & 3.2 & & & 4.89 & 1.4 & $0.13^{\star \star}$ & 3.48 & & & 4.89 & 1.37 & $0.13^{\star \star \star}$ & 3.57 \\
\hline Furloughed & & & -0.19 & 1.07 & -0.01 & -0.17 & & & -0.02 & 0.95 & -0.001 & -0.03 & & & -0.77 & 1.01 & -0.03 & -0.76 & & & -1.21 & 0.99 & -0.04 & -1.23 \\
\hline Working (t) & & & 0.71 & 0.94 & 0.02 & 0.75 & & & 0.012 & 0.83 & 0.0004 & 0.02 & & & 1.64 & 0.88 & 0.06 & 1.86 & & & 1.48 & 0.86 & 0.06 & 1.72 \\
\hline P.Unemployed & & & -0.29 & 1.05 & -0.01 & -0.27 & & & -1.51 & 0.93 & -0.05 & -1.62 & & & -1.7 & 0.99 & -0.06 & -1.71 & & & -1.49 & 0.97 & -0.05 & -1.54 \\
\hline Challenge & & & -4.88 & 1.46 & $-0.24^{\star \star}$ & -3.36 & & & 1.82 & 1.29 & 0.1 & 1.41 & & & 2.15 & 1.38 & 0.12 & 1.57 & & & 2.74 & 1.34 & $0.15^{\star}$ & 2.04 \\
\hline Commitment & & & -0.02 & 1.44 & -0.001 & -0.02 & & & -5.36 & 1.28 & $-0.31^{\star \star \star}$ & -4.18 & & & -5.74 & 1.36 & $-0.34^{\star \star \star}$ & -4.21 & & & -4.63 & 1.33 & $-0.27^{\star \star}$ & -3.48 \\
\hline Control & & & -5.93 & 1.98 & $-0.25^{\star \star}$ & -3 & & & -7.4 & 1.75 & $-0.34^{\star \star \star}$ & -4.22 & & & -9.29 & 1.87 & $-0.44^{\star \star \star}$ & -4.97 & & & -10.32 & 1.82 & $-0.48^{\star \star \star}$ & -5.67 \\
\hline Confidence & & & -3.57 & 1.73 & $-0.18^{\star}$ & -2.07 & & & -1.42 & 1.53 & -0.08 & -0.93 & & & 2.38 & 1.63 & 0.13 & 1.46 & & & 0.7 & 1.59 & 0.04 & 0.44 \\
\hline JLxChal & & & 2.41 & 3.44 & 0.03 & 0.7 & & & -1.18 & 3.05 & -0.02 & -0.39 & & & -4.74 & 3.25 & -0.07 & -1.46 & & & -6.42 & 3.17 & $-0.1^{*}$ & -2.03 \\
\hline FxChal & & & 3.19 & 2.77 & 0.06 & 1.15 & & & 3.2 & 2.46 & 0.06 & 1.3 & & & -0.07 & 2.62 & -0.001 & -0.03 & & & -0.16 & 2.55 & -0.003 & -0.06 \\
\hline WxChal & & & 5.5 & 2.46 & $0.12^{\star}$ & 2.24 & & & 1.72 & 2.19 & 0.04 & 0.78 & & & -2.42 & 2.33 & -0.06 & -1.04 & & & -0.65 & 2.27 & -0.02 & -0.29 \\
\hline PUxChal & & & 4.6 & 2.47 & 0.1 & 1.84 & & & -0.06 & 2.19 & -0.001 & -0.03 & & & -1.02 & 2.34 & -0.03 & -0.44 & & & -2.53 & 2.28 & -0.06 & -1.11 \\
\hline JLxComm & & & -1.7 & 3.03 & -0.02 & -0.55 & & & -3.59 & 2.69 & -0.05 & -1.34 & & & -5.36 & 2.87 & -0.08 & -1.87 & & & -2.31 & 2.79 & -0.04 & -0.83 \\
\hline FxComm & & & 4.12 & 2.55 & 0.08 & 1.62 & & & 1.11 & 2.26 & 0.02 & 0.49 & & & 3.57 & 2.41 & 0.08 & 1.48 & & & 1.37 & 2.34 & 0.03 & 0.59 \\
\hline WxComm & & & -3.23 & 2.34 & -0.08 & -1.38 & & & -3.73 & 2.07 & -0.1 & -1.8 & & & -3.88 & 2.21 & -0.1 & -1.76 & & & -0.99 & 2.15 & -0.03 & -0.46 \\
\hline PUxComm & & & -0.01 & 2.37 & 0.0003 & -0.01 & & & 0.39 & 2.11 & 0.01 & 0.18 & & & 3.31 & 2.24 & 0.09 & 1.48 & & & 3.6 & 2.19 & 0.1 & 1.65 \\
\hline JLxCont & & & -0.37 & 4.11 & -0.004 & -0.09 & & & 0.76 & 3.64 & 0.01 & 0.21 & & & 5.18 & 3.88 & 0.07 & 1.33 & & & 9.96 & 3.78 & $0.13^{\star \star}$ & 2.63 \\
\hline FxCont & & & -8.9 & 3.62 & $-0.15^{\star}$ & -2.45 & & & 4.13 & 3.21 & 0.07 & 1.29 & & & 4.19 & 3.42 & 0.08 & 1.22 & & & 3.36 & 3.33 & 0.06 & 1.01 \\
\hline WxCont & & & -3.23 & 3.28 & -0.06 & -0.98 & & & -2.33 & 2.91 & -0.05 & -0.8 & & & -0.87 & 3.1 & -0.02 & -0.28 & & & -3.64 & 3.02 & -0.07 & -1.21 \\
\hline PUxCont & & & -6.31 & 3.42 & -0.12 & -1.85 & & & 2.38 & 3.03 & 0.05 & 0.79 & & & 1.74 & 3.23 & 0.04 & 0.54 & & & 1.78 & 3.14 & 0.04 & 0.57 \\
\hline JLxConf & & & 0.57 & 4.18 & 0.01 & 0.14 & & & 1.71 & 3.71 & 0.03 & 0.46 & & & 5.52 & 3.95 & 0.08 & 1.4 & & & 1.98 & 3.85 & 0.03 & 0.51 \\
\hline FxConf & & & -0.97 & 3.1 & -0.02 & -0.31 & & & -6.91 & 2.75 & $-0.15^{\star}$ & -2.51 & & & -5.6 & 2.93 & -0.12 & -1.91 & & & -4.06 & 2.85 & -0.09 & -1.42 \\
\hline WxConf & & & 0.37 & 3.1 & 0.01 & 0.12 & & & 0.93 & 2.75 & 0.02 & 0.34 & & & 4.1 & 2.93 & 0.1 & 1.4 & & & 2.79 & 2.86 & 0.07 & 0.98 \\
\hline PUxConf & & & -1.48 & 2.76 & -0.04 & -0.54 & & & -2.98 & 2.45 & -0.08 & -1.21 & & & -3.26 & 2.61 & -0.09 & -1.25 & & & -4.31 & 2.55 & -0.11 & -1.69 \\
\hline
\end{tabular}

${ }^{*} P<0.05,{ }^{* *} P<0.01,{ }^{* *} P<0.005$. 
a significant contribution to the model. The interaction terms working (traveling) $x$ Challenge and furloughed $x$ Control were also significantly associated with state anxiety (see Figures 1, 2 , respectively).

The final model for depression was statistically significant $\left[F_{(24,690)}=25.76 ; p<0.001\right]$ and explained $47.3 \%$ of variance. Job loss, Commitment and Control made a significant contribution to the model. The interaction term furloughed $x$ Confidence was also significantly associated with depression (see Figure 3).

The final model for anxiety (DASS21) was statistically significant $\left[F_{(24,689)}=16.98 ; p<0.001\right]$ and explained $37.2 \%$ of variance. Job loss, Commitment and Control made a significant contribution to the model. There were no significant associations between the outcome and the interaction terms.

The final model for stress was statistically significant $\left[F_{(24,689)}\right.$ $=19.8 ; p<0.001]$ and explained $40.8 \%$ of variance. Job loss, Challenge, Commitment and Control made a significant contribution to the model. The interaction terms job loss $x$ Challenge and Job loss $x$ Control were also significantly associated with stress (see Figures 4, 5).

\section{DISCUSSION}

Individuals who had lost their jobs during the pandemic reported higher levels of depression, anxiety and stress; and lower levels of MT, compared to those who had remained employed. However, across the samples, self-reported symptoms of depression, anxiety and stress were less severe among mentally tough individuals, with MT having a moderating effect on the impact of employment status on mental health. The present study's findings, and their practical implications, are discussed further below.

Participants from Sample B reported higher scores on the DASS21 subscales in comparison to Sample A. One possible explanation for the differences in scores could be the timing of data collection periods, with the majority of participants from Sample B completing the survey at a later period during the pandemic (on May 25th, 2020). Higher death rates, stricter lockdown regulation and greater financial impact on the economy may have led to higher reports of stress, anxiety and depression. However, findings from other COVID-19 studies found that DASS21 scores remained stable throughout the initial lockdown period [see (15)]. The demographic differences between the samples could also explain the differences in scores. Sample A was an exclusively UK cohort whereas Sample B was comprised of participants from a diverse range of countries. Although DASS21 scores appear to be consistent cross-culturally (62), differences in each country's response to controlling the virus may have resulted in changes to the negative affective states of the participants - further evidence on individuals' attitudes to the pandemic would be needed to support this assertion. Other demographic factors that could explain the higher DASS21 scores within Sample B include a greater proportion of men and individuals who had lost their jobs during the pandemic. However, due to the demographic and methodological (data collection platform and time) differences between the two datasets, it is not possible to confidently identify the lead contributor for the disparity in DASS21 scores. More importantly, our discussion of the results focusses on the disparities in negative affective states between the current samples and pre-COVID-19 samples from previous research.

Participants from both samples reported noticeably higher levels of depression, anxiety and stress than participants from previous pre-COVID-19 research. Crawford et al. (63) reported mean scores of 5.14, 3.48, 7.98, and 36.35 for depression, anxiety (DASS21), stress and STAI-Y1, respectively, for Australian adults during 1995-2000 ${ }^{1}$. This was proportionately lower than the mean scores of participants from Samples A (10.99, 7.01, 13.32, and 42.7$)$ and $B(16.32,15.2,17.48$, and 44.36). Whilst we cannot definitively confirm the cause for the disparity in scores, it is possible that the distinct differences in affective states could be a result of situational factors brought on by the recent pandemic - however, this ascription should only be taken as speculation due to Crawford's sample not being studied by the present researchers.

\section{Association Between MT and Negative Affective States}

We hypothesized that MT traits would be negatively associated with depression (H1), anxiety (H2), and stress (H3). Partial correlations identified significant negative associations between all MT traits and the depression, anxiety and stress measures, supporting the first three hypotheses. However, after entering the predictors into hierarchical regression models and controlling for trait anxiety, the association between some of the MT traits and the negative affective states were not significant. The reduction in significant associations could be attributed to the high levels of inter-correlation between the MT traits and trait anxiety reducing the additional contribution each predictor made to the model. There were more significant associations between the MT predictors and negative affective states within Sample B, with all four forms of MT being associated with depression, anxiety (DASS21) and stress; and the Control variable being associated with STAI-Y1 as well. The increased level of associations within Sample B could be due to the participants' higher levels of anxiety, stress and depression accentuating the observed relationships between MT and the aforementioned states. Additionally, and unexpectedly, some of the associations between MT and negative affective states appeared to show a positive relationship in the final regression models. This was most notable within Sample $\mathrm{B}$, where the Challenge and Confidence traits had positive standardized coefficients when predicting stress, depression and anxiety (DASS21); and within Sample A, where Commitment had a positive coefficient when predicting STAI-Y1. However, the directions of these associations were not reflected in the initial partial correlations, nor were they present within the moderation analysis of the combined sample, leading the authors to speculate that they may have been the result of a suppressor effect from other MT traits. ${ }^{1}$ The raw DASS21 scores were multiplied by 2 , as instructed by the DASS 21 manual
[see (49)] to make the scores comparable to the present samples'. 


\section{Challenge as a moderator of anxiety (STAI-Y1)}

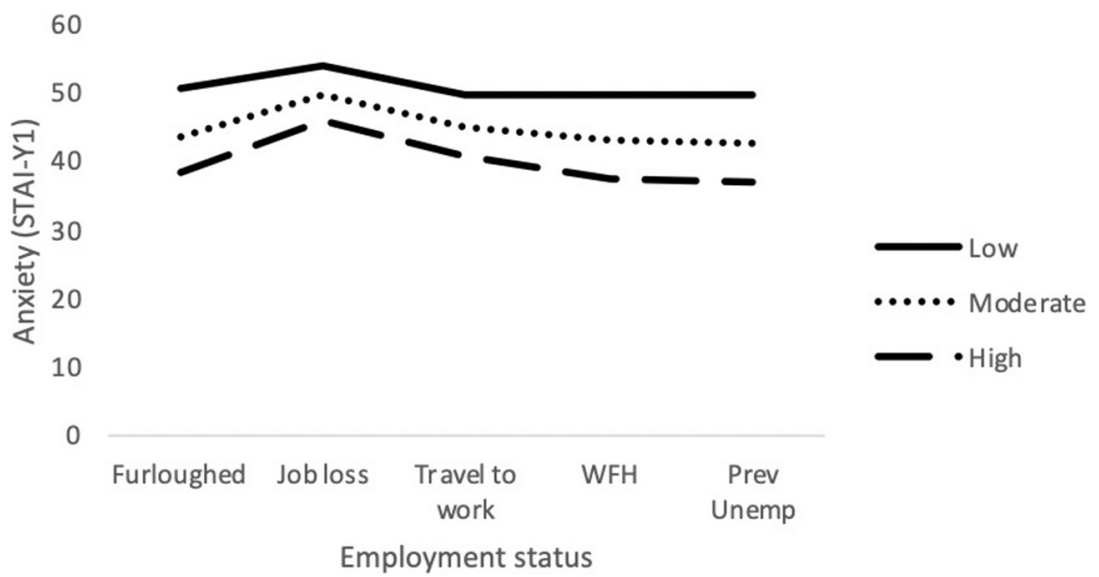

FIGURE 1 | Interaction between job outcome and Challenge for State Anxiety. WFH, Employed (working from home); Prev Unemp, previously unemployed.

\section{Control as a moderator of anxiety (STAI-Y1)}

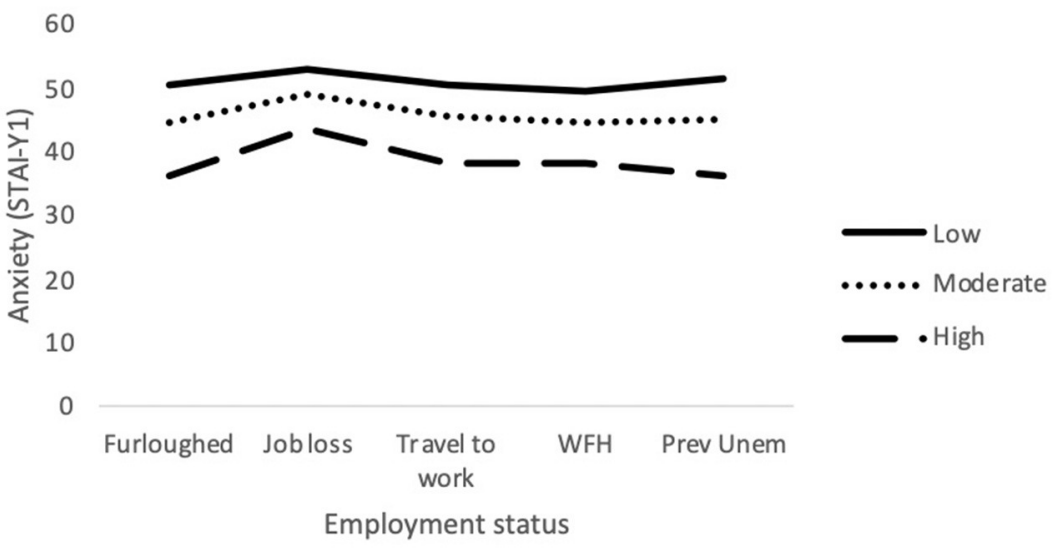

FIGURE 2 | Interaction between job outcome and Control for State Anxiety. WFH, Employed (working from home); Prev Unemp, previously unemployed.

The relationship between MT and stress can be explained using the cognitive-transactional stress theory. According to the model, stress is provoked when the perceived demands of a situation outweigh an individual's ability to cope with the stressor (64). Haghighi and Gerber (38) explained that mentally tough individuals may perceive events as being less stressful due to perceiving their selves as having greater control over the situation, being more capable of staying committed under stress and being better equipped to overcome the issue. Furthermore, Clough et al. (35) defined the Challenge element of MT as the ability to regard problematic events as challenges rather than threats. The same characteristics that allow mentally tough individuals to perceive threatening situations as being less stressful can also reduce the level of anxiety they exhibit. That is, mentally tough individuals with greater confidence in their abilities and perceived control over stressful events are less likely to worry or exhibit fear over them. The relationship between depression and MT was also to be expected, given the clear incompatibility between MT traits and depressive symptoms (i.e., hopelessness, withdrawal and avoidance) (38).

\section{Changes in Employment Status During the Pandemic}

Results indicated that job/business loss was a significant predictor of anxiety, depression and stress, supporting hypotheses 4, 5, and 6. Our findings align with previous research that had identified a link between job loss and depressive symptoms (65, 66), and also with more recent research showing a relationship between temporary job loss and stress during the COVID19 pandemic (2). Mimoun and colleagues explained that jobs "provide individuals a sense of confidence, self-esteem, and control" (2, p. 184). Thus, the removal of one's employment is likely to reduce their sense of value and purpose, consequently 


\section{Confidence as a moderator of depression}

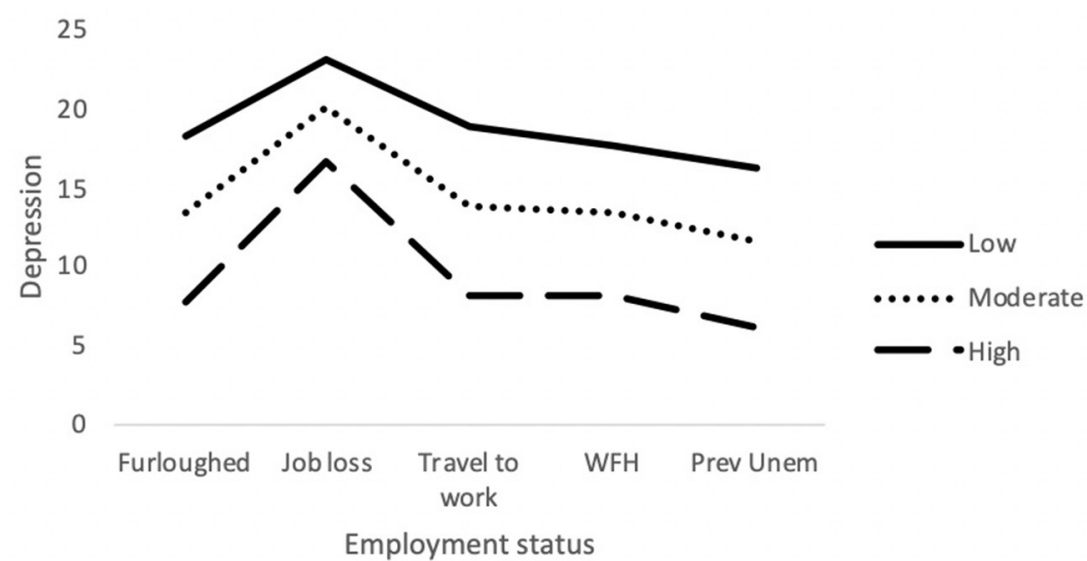

FIGURE 3 | Interaction between job outcome and Confidence for Depression. WFH, Employed (working from home); Prev Unemp, previously unemployed.

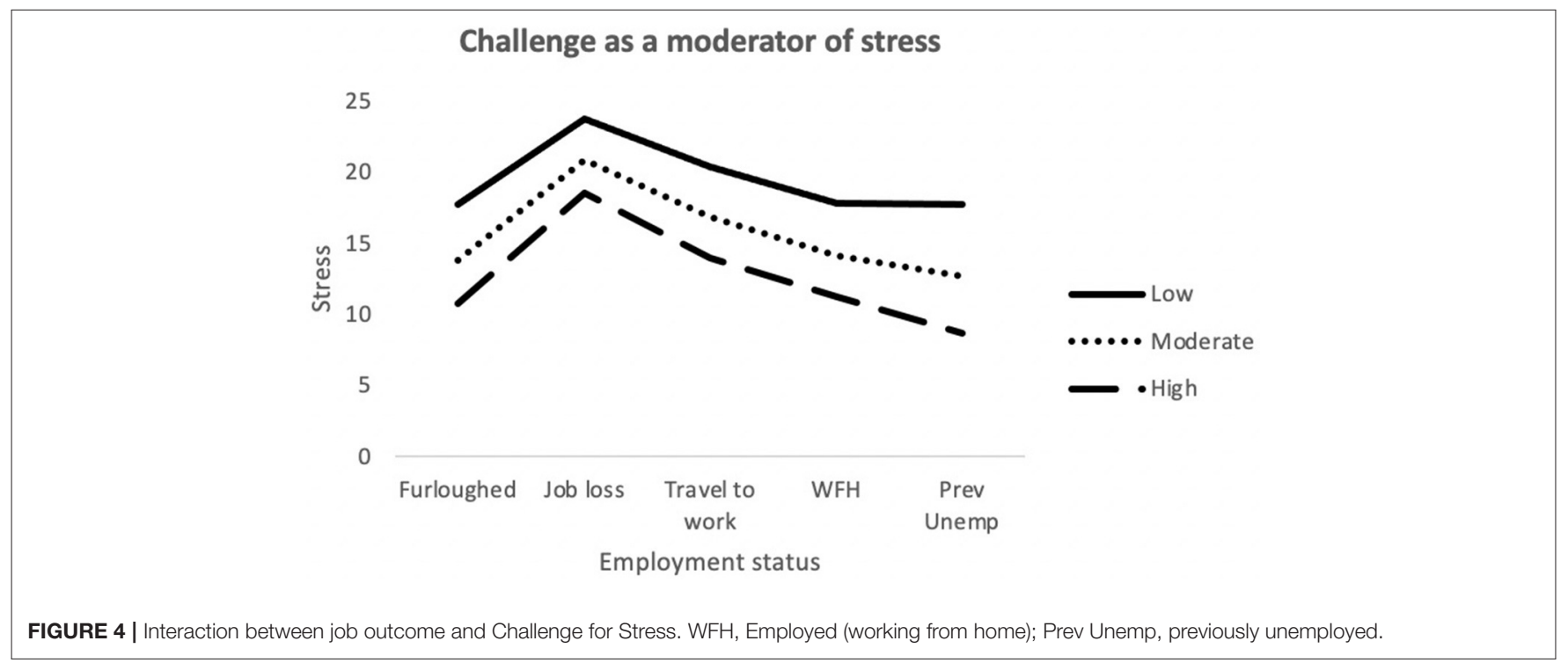

leading to an increase in depressive symptoms. The effects of recent unemployment with stress and anxiety were also to be expected as the economic hardship brought on by unemployment can often provoke heightened levels of stress and anxiety amongst individuals lacking financial stability (67).

Moderation analyses were used to assess the utility of MT as a protective factor against the adverse effects brought on by recent changes in employment. Multiple significant interactions between MT and employment status were identified when attempting to predict depression, anxiety and stress. For anxiety (STAI-Y1), there were significant interactions between traveling to work and Challenge scores. As illustrated in Figure 1, among participants who were traveling to work during the pandemic, those who possessed low levels of the Challenge trait still exhibited greater levels of anxiety, despite still being in employment. The Challenge characteristic is defined as an individual's tendency to adapt to changing environments and perceive potential threats as opportunities for growth (35). As such, individuals scoring low on this trait may have been less able to overcome the changes in their work environments and more likely to worry about the increased risk of viral contamination. There was also an interaction effect between getting furloughed and Control scores. Furloughed individuals with high Control scores reported less anxiety than those with moderate and low scores. Furloughed individuals with high levels of perceived Control may see temporary unemployment as a more manageable and solvable issue and would be better equipped to manage their emotions whilst awaiting their return to work. For depression, there was a significant interaction between getting furloughed and Confidence. It is possible that individuals with higher levels of confidence would be less likely to interpret temporary unemployment as a reflection of their professional worth and thus, would be less likely to experience depressive symptoms as a result. Finally, for stress, 


\section{Control as a moderator of stress}

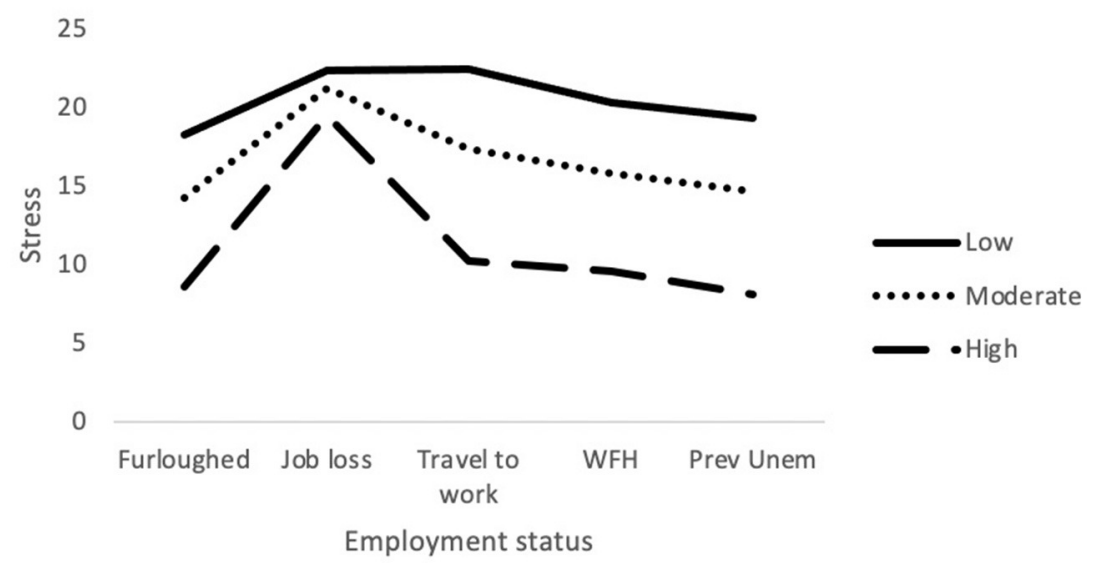

FIGURE 5 | Interaction between job outcome and Control for Stress. WFH, Employed (working from home); Prev Unemp, previously unemployed.

job loss significantly interacted with both Challenge and Control. The perceived stressfulness of an event is influenced by the individual's perceived ability to cope with the new threat (68). Research has shown that high MT is associated with both coping self-efficacy and coping effectiveness (69, 70). Furthermore, individuals who score low on the Challenge scale are less able to adapt to changing environments than individuals with higher scores. As a result, the loss of employment is likely to be handled less effectively by people who are not mentally tough. Individuals with high levels of Control generally reported lower levels of stress in comparison to participants with low or moderate levels. However, Control did not appear to provide much protection against stress for those who had lost their job/business during the pandemic. As Figure 5 illustrates, participants with high levels of Control still reported high levels of stress, similar to the levels reported by participants with lower levels of Control. The findings suggest that whilst the Control element of MT can allow individuals to cope with stress better during the pandemic, the perceived stressfulness of unemployment during the pandemic may outweigh their perceived abilities to deal with situation.

\section{Stability of Mental Toughness During the Pandemic}

The present findings suggest that MT could be susceptible to environmental influence. Whilst the present study's crosssectional design cannot prove that changes in employment status will have had a direct impact on MT, comparisons between the employment status groups indicated that those who had lost their jobs/business or become furloughed reported lower levels of MT than those who were working from home. Sudden loss of employment can have a negative impact on an individual's perceived level of control over their life and confidence in their own abilities. Previous research supports the notion of MT being a dynamic trait, however changes in MT have typically been measured in relation to growth over time $(59,71)$; our findings suggest that MT may also be susceptible to regressing.

Our observations suggest that despite the protective utility for mental health, MT is susceptible to environmental influence.
Based on these observations, we argue that attempts to preserve and strengthen public MT should and could be attempted by health organizations. The notion of using MT building strategies to improve the well-being of individuals has been proposed in the past. Gucciardi and Jones (44) proposed using interventions that targeted MT as a way of improving the well-being of vulnerable individuals and Gerber et al. (37) argued that training MT would be particularly useful for supporting the mental health of individuals who may be difficult to reach with more typical health interventions. The potential for improving MT through clinical practice has been evidenced within sport-related contexts. Psychological skills training (PST) interventions [e.g., (72)] have been successful in using routine coaching activities (including goal setting, visualization, relaxation and thought stoppage) to enhance psychological qualities that underpin MT (i.e., hardiness, self-esteem, self-efficacy, dispositional optimism, positive affectivity) $(73,74)$. PST interventions could therefore provide individuals vulnerable to stress, depression and anxiety during a pandemic- such as recently unemployed individualswith the necessary psychological prerequisites to maintain emotional resilience. This is because the aforementioned qualities of MT are incompatible with symptoms of stress and depression (e.g., irritability and hopelessness) and as such could mitigate the adverse effects of a pandemic.

\section{LIMITATIONS AND DIRECTIONS FOR FUTURE RESEARCH}

The present study is the first to examine the role of MT as a protective factor for mental health during the Covid19 pandemic. Undoubtably, some limitations exist that require acknowledgment. Firstly, the cross-sectional design of the study meant that we were unable to measure the respondents' MT and state of mental health before or at the early stages of the pandemic. As a result, we cannot reliably determine how much of an impact the pandemic had on MT and mental 
health. A longitudinal design would have enabled us to assess the utility of MT as a protective factor against the pandemic's adverse effects on mental health more accurately by observing the interactions between MT and time on self-reported stress, anxiety and depression. Similarly, without a longitudinal design, it is difficult to confidently determine the extent to which MT can be influenced by environmental factors such as job loss. Whilst it is impossible to retrospectively assess MT and mental health scores of individuals at the start of the pandemic, new longitudinal research monitoring individuals' MT scores as society continues to adapt to the effects of COVID-19 could provide further insight into the stability of MT during a pandemic. Building on this, future research should examine whether interventions aimed at improving MT could succeed and whether the interventions can lead to reductions in stress, anxiety and depression.

A second data collection (Sample B) was conducted to gather a larger sample for inferential testing and to determine whether the associations between MT and negative affective states could be replicated within a sample that differed geographically. Unfortunately, we were unable to control or match the sample for other potential extraneous variables (i.e., time of data collection, gender and employment distribution). Due to multiple salient differences between the samples, it is not possible to reliably ascribe an explanation for the differences in negative affective state.

Finally, our study measured employment status through five nominal categories (job/business loss during the pandemic, furloughed, traveling to work, working from home and previously unemployed) but failed to distinguish those who were retired or students. It is possible that these individuals may have had a confounding effect on the observed relationship between employment status and mental health. This is possible given that many students have reported experiencing greater psychological impact due to disruption to their educational environments (75). In addition to this, the conditions of temporary unemployment (furloughed) will have differed for each participant. Whilst many furloughed individuals within the UK still received some financial support during the period, this was not the case for many others (2). Thus, we acknowledge that a more precise measure of employment could have provided us with a more complete understanding of the effects of the pandemic on different groups.

\section{CONCLUSION}

The observed severity of depression, anxiety and stress within our samples highlight the psychological impact of the current climate, however the results also suggest that MT could supress some of these effects. Thus, the practical implications of the present findings highlight the potential for MT-based interventions to be used as a means for boosting individuals' resilience to the adverse mental health effects of the pandemic. Past research has demonstrated that not only can MT-related traits (such as hardiness and positive affectivity) be enhanced through PST, but that such enhancements could help build up resilience to negative emotions within stressful situations. Despite this, our understanding of the mental impact of the pandemic is still at a relatively early stage and further longitudinal research is required to better understand the psychological consequences of COVID19. A practical step forward from the current research would be to determine whether MT can be improved through short-term interventions and whether such an approach could help improve the emotional resilience of individuals during a pandemic.

\section{DATA AVAILABILITY STATEMENT}

The datasets presented in this study can be found in online repositories. The names of the repository/repositories and accession number(s) can be found at: https://osf.io/zebhj.

\section{ETHICS STATEMENT}

This study involving human participants was reviewed and approved by the ethics review panel from the University of Huddersfield. The patients/participants provided their written informed consent to participate in this study.

\section{AUTHOR CONTRIBUTIONS}

The project was created by DM and PC. DM conducted the data analysis, data collection, and manuscript writeup. ND contributed to the writeup of the introduction and methodology and provided guidance on the research design. $\mathrm{AD}$ contributed to the writeup of the results. PC contributed to the writeup of the introduction and design of the study. KP provided guidance on the analytical protocol, study design, and contributed to the writeup of the results. SH contributed to the design of the study and to data collection. DC and CL contributed to data collection and the editing of the manuscript. All authors contributed to the article and approved the submitted version.

\section{FUNDING}

The project received internal funding from the Center for Cognition and Neuroscience, University of Huddersfield to assist with data collection of Sample B.

\section{ACKNOWLEDGMENTS}

The authors would like to thank Miss Mollie Hood for her assistance with the sampling procedure. 


\section{REFERENCES}

1. Galea S, Merchant RM, Lurie N. The mental health consequences of COVID-19 and physical distancing: The need for prevention and early intervention. JAMA Internal Med. (2020) 180:817-8. doi: 10.1001/jamainternmed.2020.1562

2. Mimoun E, Ben Ari A, Margalit D. Psychological aspects of employment instability during the COVID-19 pandemic. Psychol Trauma. (2020) 12:S183. doi: $10.1037 /$ tra0000769

3. Rajkumar RP. COVID-19 and mental health: a review of the existing literature. Asian J Psychiatr. (2020) 102066. doi: 10.1016/j.ajp.2020.102066

4. Xiao H, Zhang Y, Kong D, Li S, Yang N. The effects of social support on sleep quality of medical staff treating patients with coronavirus disease 2019 (COVID-19) in January and February 2020 in China. Med Sci Monitor. (2020) 26:e923549-1. doi: 10.12659/MSM.923921

5. Xiao H, Zhang Y, Kong D, Li S, Yang N. Social capital and sleep quality in individuals who self-isolated for 14 days during the coronavirus disease 2019 (COVID-19) outbreak in January 2020 in China. Med Sci Monitor. (2020) 26:e923921.

6. Pompili M, Innamorati M, Lamis DA, Erbuto D, Venturini P, Ricci F, et al. The associations among childhood maltreatment, "male depression" and suicide risk in psychiatric patients. Psychiatr Res. (2014) 220:5718. doi: 10.1016/j.psychres.2014.07.056

7. Serafini G, Pompili M, Innamorati M, Gentile G, Borro M, Lamis DA, et al. Gene variants with suicidal risk in a sample of subjects with chronic migraine and affective temperamental dysregulation. Eur Rev Med Pharmacol Sci. (2012) 16:1389-98

8. Chatterjee SS, Malathesh Barikar C, Mukherjee A. Impact of COVID-19 pandemic on pre-existing mental health problems. Asian J Psychiatr. (2020) 51:102071. doi: 10.1016/j.ajp.2020.102071

9. Bao Y, Sun Y, Meng S, Shi J, Lu L. 2019-nCoV epidemic: address mental health care to empower society. Lancet. (2020) 395:e37-8. doi: 10.1016/S0140-6736(20)30309-3

10. DiGiovanni C, Conley J, Chiu D, Zaborski J. Factors influencing compliance with quarantine in Toronto during the 2003 SARS outbreak. Biosec Bioterrorism. (2004) 2:265-72. doi: 10.1089/bsp.2004.2.265

11. Ho CS, Chee CY, Ho RC. Mental health strategies to combat the psychological impact of COVID-19 beyond paranoia and panic. Ann Acad Med. (2020) 49:155-60. Available online at: http://www.anmm.org.mx/descargas/ Ann-Acad-Med-Singapore.pdf

12. Collie A, Sheehan L, van Vreden C, Grant G, Whiteford P, Petrie D, et al. Psychological distress among people losing work during the COVID-19 pandemic in Australia. MedRxiv. (2020). doi: 10.1101/2020.05.06.20093773

13. Zhang SX, Wang Y, Rauch A, Wei F. Unprecedented disruption of lives and work: Health, distress and life satisfaction of working adults in China one month into the COVID-19 outbreak. Psychiatr Res. (2020) 288:112958. doi: 10.1016/j.psychres.2020.112958

14. Burgard SA, Kalousova L, Seefeldt KS. Perceived job insecurity and health: the Michigan recession and recovery study. J Occupat Environ Med. (2012) 54:1101-6. doi: 10.1097/JOM.0b013e3182677dad

15. Wang C, Pan R, Wan X, Tan Y, Xu L, Ho CS, et al. Immediate psychological responses and associated factors during the initial stage of the 2019 coronavirus disease (COVID-19) epidemic among the general population in China. Int J Environ Res Public Health. (2020) 17:1729. doi: 10.3390/ijerph17051729

16. Norton PJ. Depression Anxiety and Stress Scales (DASS-21): psychometric analysis across four racial groups. Anxiety Stress Coping. (2007) 20:253-65. doi: 10.1080/10615800701309279

17. Wang C, Pan R, Wan X, Tan Y, Xu L, McIntyre RS, et al. A longitudinal study on the mental health of general population during the COVID-19 epidemic in China. Brain Behav Immun. (2020) 87:40-8. doi: 10.1016/j.bbi.2020.04.028

18. Huang Y, Zhao N. Generalized anxiety disorder, depressive symptoms and sleep quality during COVID-19 outbreak in China: a web-based cross-sectional survey. Psychiatr Res. (2020) 288:112954. doi: 10.1016/j.psychres.2020.112954

19. Huppert FA. Psychological well-being: Evidence regarding its causes and consequences. Appl Psychol. (2009) 1:13764. doi: $10.1111 / j .1758-0854.2009 .01008 . x$
20. Lin Y, Mutz J, Clough PJ, Papageorgiou KA. Mental toughness and individual differences in learning, educational and work performance, psychological well-being, and personality: A systematic review. Front Psychol. (2017) 8:1345. doi: 10.3389/fpsyg.2017.01345

21. Dagnall N, Denovan A, Papageorgiou KA, Clough PJ, Parker A, Drinkwater KG. Psychometric assessment of shortened mental toughness questionnaires (MTQ): factor structure of the MTQ-18 and the MTQ-10. Front Psychol. (2019) 10:1933. doi: 10.3389/fpsyg.2019.01933

22. Drinkwater K, Dagnall N, Denovan A, Parker A. The moderating effect of mental toughness: perception of risk and belief in the paranormal. Psychol Rep. (2019) 122:268-87. doi: 10.1177/0033294118756600

23. Crust L. Mental toughness in sport: a review. Int J Sport Exercise Psychol. (2007) 5:270-90. doi: 10.1080/1612197X.2007.9671836

24. Alikhani M, Ebrahimi A, Farnia V, Khazaie H, Radmehr F, Mohamadi E, et al. Effects of treatment of sleep disorders on sleep, psychological and cognitive functioning and biomarkers in individuals with HIV/AIDS and under methadone maintenance therapy. J Psychiatr Res. (2020) 130:26072. doi: 10.1016/j.jpsychires.2020.07.043

25. Farnia V, Gharehbaghi H, Alikhani M, Almasi A, Golshani S, Tatari F, et al. Efficacy and tolerability of adjunctive gabapentin and memantine in obsessive compulsive disorder: double-blind, randomized, placebo-controlled trial. J Psychiatr Res. (2018) 104:137-43. doi: 10.1016/j.jpsychires.2018. 07.008

26. Jahangard L, Rahmani A, Haghighi M, Ahmadpanah M, Sadeghi Bahmani D, Soltanian AR, et al. "Always look on the bright side of life!"-higher hypomania scores are associated with higher mental toughness, increased physical activity, and lower symptoms of depression and lower sleep complaints. Front Psychol. (2017) 8:2130. doi: 10.3389/fpsyg.2017.02130

27. Papageorgiou KA, Denovan A, Dagnall N. The positive effect of narcissism on depressive symptoms through mental toughness: narcissism may be a dark trait but it does help with seeing the world less grey. Euro Psychiatr. (2019) 55:74-9. doi: 10.1016/j.eurpsy.2018.10.002

28. Papageorgiou KA, Gianniou FM, Wilson P, Moneta GB, Bilello D, Clough PJ. The bright side of dark: exploring the positive effect of narcissism on perceived stress through mental toughness. Pers Individ Dif. (2019) 139:11624. doi: $10.1016 /$ j.paid.2018.11.00

29. Sabouri S, Gerber M, Bahmani DS, Lemola S, Clough PJ, Kalak N, et al. Examining dark triad traits in relation to mental toughness and physical activity in young adults. Neuropsychiatr Dis Treat. (2016) 12:229. doi: 10.2147/NDT.S97267

30. Sadeghi Bahmani D, Esmaeili L, Shaygannejad V, Gerber M, Kesselring J, Lang UE, et al. Stability of mental toughness, sleep disturbances, and physical activity in patients with multiple sclerosis (MS) - a longitudinal and pilot study. Front Psychiatr. (2018) 9:182. doi: 10.3389/fpsyt.2018. 00182

31. Sadeghi Bahmani D, Gerber M, Kalak N, Lemola S, Clough PJ, Calabrese $\mathrm{P}$, et al. Mental toughness, sleep disturbances, and physical activity in patients with multiple sclerosis compared to healthy adolescents and young adults. Neuropsychiatr Dis Treat. (2016) 12:1571-9.1571.doi: 10.2147/NDT.S1 11208

32. Sadeghi Bahmani D, Hatzinger M, Gerber M, Lemola S, Clough PJ, Perren S, et al. The origins of mental toughness-prosocial behavior and low internalizing and externalizing problems at age 5 predict higher mental toughness scores at age 14. Front Psychol. (2016) 7:1221. doi: 10.3389/fpsyg.2016.01221

33. Jones G. What is this thing called mental toughness? $J$ Appl Sport Psychol. (2002) 14:205-18. doi: 10.1080/10413200290 103509

34. Gucciardi DF. Mental toughness: progress and prospects. Curr Opin Psychol. (2017) 16:17-23. doi: 10.1016/j.copsyc.2017.03.010

35. Clough P, Earle K, Sewell D. Mental toughness: the concept and its measurement. Solutions in sport psychology. In: Cockerill IM, editor. Solutions in Sport Psychology. London: Cengage Learning, EMEA (2002). p. 32-43.

36. Gerber M, Best S, Meerstetter F, Walter M, Ludyga S, Brand S, et al. Effects of stress and mental toughness on burnout and depressive symptoms: A prospective study with young elite athletes. J Sci Med Sport. (2018) 21:12005. doi: 10.1016/j.jsams.2018.05.018 
37. Gerber M, Kalak N, Lemola S, Clough PJ, Perry JL, Pühse U, et al. Are adolescents with high mental toughness levels more resilient against stress? Stress Health. (2013) 29:164-71. doi: 10.1002/smi.2447

38. Haghighi M, Gerber M. Does mental toughness buffer the relationship between perceived stress, depression, burnout, anxiety, and sleep? Int J Stress Manage. (2019) 26:297-305. doi: 10.1037/str0000106

39. Song L, Wang Y, Li Z, Yang Y, Li H. Mental health and work attitudes among people resuming work during the COVID-19 pandemic: a cross-sectional study in China. Int J Environ Res Public Health. (2020) 17:5059. doi: 10.3390/ijerph17145059

40. Horsburgh VA, Schermer JA, Veselka L, Vernon PA. A behavioural genetic study of mental toughness and personality. Personal Indiv Diff. (2009) 46:1005. doi: 10.1016/j.paid.2008.09.009

41. Veselka L, Schermer JA, Martin RA, Vernon PA. Laughter and resiliency: A behavioral genetic study of humor styles and mental toughness. Twin Res Hum Gene. (2010) 13:442-9. doi: 10.1375/twin.13.5.442

42. Onley M, Veselka L, Schermer JA, Vernon PA. Survival of the scheming: a genetically informed link between the dark triad and mental toughness. Twin Res Hum Gene. (2013) 16:1087-95. doi: 10.1017/thg.2013.66

43. Bell JJ, Hardy L, Beattie S. Enhancing mental toughness and performance under pressure in elite young cricketers: a 2-year longitudinal intervention. Sport Exercise Perform Psychol. (2013) 2:281-97. doi: 10.1037/a0033129

44. Gucciardi DF, Jones MI. Beyond optimal performance: mental toughness profiles and developmental success in adolescent cricketers. J Sport Exercise Psychol. (2012) 34:16-36. doi: 10.1123/jsep.34.1.16

45. Spector PE. Do not cross me: optimizing the use of cross-sectional designs. $J$ Bus Psychol. (2019) 34:125-37. doi: 10.1007/s10869-018-09613-8

46. Krishnaveni R, Deepa R. Controlling common method variance while measuring the impact of emotional intelligence on well-being. Vikalpa. (2013) 38:41-8. doi: 10.1177/0256090920130104

47. Podsakoff PM, MacKenzie SB, Lee JY, Podsakoff NP. Common method biases in behavioral research: A critical review of the literature and recommended remedies. J Appl Psychol. (2003) 88:879-903. doi: 10.1037/0021-9010.88.5.879

48. Denovan A, Dagnall N, Drinkwater K, Parker A, Neave N. Conspiracist beliefs, intuitive thinking, and schizotypal facets: a further evaluation. Appl Cognit Psychol. (2020) 34:1394-405. doi: 10.1002/acp.3716

49. Drinkwater KG, Denovan A, Dagnall N. Lucid dreaming, nightmares, and sleep paralysis: associations with reality testing deficits and paranormal experience/belief. Front Psychol. (2020) 11:471. doi: 10.3389/fpsyg.2020.00471

50. Paolacci G, Chandler J. Inside the turk: understanding mechanical turk as a participant pool. Curr Direct Psychol Sci. (2014) 23:1848. doi: 10.1177/0963721414531598

51. Lovibond PF, Lovibond SH. The structure of negative emotional states: comparison of the depression anxiety stress scales (DASS) with the beck depression and anxiety inventories. Behav Res Therap. (1995) 33:335-43.

52. Antony MM, Bieling PJ, Cox BJ, Enns MW, Swinson RP. Psychometric properties of the 42-item and 21-item versions of the depression anxiety stress scales in clinical groups and a community sample. Psychol Assessment. (1998) 10:176-81. doi: 10.1037/1040-3590.10.2.176

53. Hegney DG, Rees CS, Eley R, Osseiran-Moisson R, Francis K. The contribution of individual psychological resilience in determining the professional quality of life of Australian nurses. Front Psychol. (2015) 6:1613. doi: 10.3389/fpsyg.2015.01613

54. Lovibond SF, Lovibond PF. Manual for the Depression Anxiety Stress Scales. Sydney, NSW: The Psychology Foundation of Australia (2004).

55. Spielberger CD. Manual for the State-Trait Anxiety Inventory (Form Y). Palo Alto, CA: Mind Garden (1983). doi: 10.1037/t06496-000

56. Bados A, Gómez-Benito J, Balaguer G. The state-trait anxiety inventory, trait version: does it really measure anxiety? J Personal Assessment. (2010) 92:560-7. doi: 10.1080/00223891.2010.513295

57. Vitasari P, Wahab MNA, Herawan T, Othman A, Sinnadurai SK. Re-test of State Trait Anxiety Inventory (STAI) among engineering students in Malaysia: reliability and validity tests. Proc Soc Behav Sci. (2011) 15:38438. doi: 10.1016/j.sbspro.2011.04.383

58. Levy AR, Polman RC, Clough PJ, Marchant DC, Earle K. Mental toughness as a determinant of beliefs, pain, and adherence in sport injury rehabilitation. $J$ Sport Rehabilit. (2006) 15:245-54. doi: 10.1123/jsr.15.3.245
59. Nicholls AR, Polman RC, Levy AR, Backhouse SH. Mental toughness, optimism, pessimism, and coping among athletes. Personal Individ Diff. (2008) 44:1182-92. doi: 10.1016/j.paid.2007.11.011

60. Tabachnick BG, Fidell LS. Using Multivariate Statistics (6th ed.). Boston, MA: Pearson (2013).

61. Cohen J. Statistical Power Analysis for the Behavioral Sciences. 2nd ed. Hillsdale, NJ: Lawrence Erlbaum (1988).

62. Mellor D, Vinet EV, Xu X, Mamat NHB, Richardson B, Román F. Factorial invariance of the DASS-21 among adolescents in four countries. Euro J Psychol Assessment. (2015) 31:138-42. doi: 10.1027/1015-5759/ a000218

63. Crawford J, Cayley C, Lovibond PF, Wilson PH, Hartley C. Percentile norms and accompanying interval estimates from an Australian general adult population sample for self-report mood scales (BAI, BDI, CRSD, CES-D, DASS, DASS-21, STAI-X, STAI-Y, SRDS, and SRAS). Aust Psychol. (2011) 46:3-14. doi: 10.1111/j.1742-9544.2010.00003.x

64. Lazarus RS, Folkman S. Stress, Appraisal, and Coping. New York, NY: Springer publishing company (1984).

65. Brand JE, Levy BR, Gallo WT. Effects of layoffs and plant closings on subsequent depression among older workers Res Aging. (2008) 30:70121. doi: $10.1177 / 0164027508322574$

66. Burgard SA, Brand JE, House JS. Toward a better estimation of the effect of job loss on health. J Health Soc Behav. (2007) 48:36984. doi: 10.1177/002214650704800403

67. Mamun MA, Akter S, Hossain I, Faisal MTH, Rahman MA, Arefin A, et al. Financial threat, hardship and distress predict depression, anxiety and stress among the unemployed youths: a Bangladeshi multi-city study. J Affect Disord. (2020) 276:1149-58. doi: 10.1016/j.jad.2020.06.075

68. Sherman DK, Cohen GL. The psychology of self-defense: self-affirmation theory. Adv Exp Soc Psychol. (2006) 38:183242. doi: 10.1016/S0065-2601(06)38004-5

69. Cowden RG, Fuller DK, Anshel MH. Psychological predictors of mental toughness in elite tennis: an exploratory study in learned resourcefulness and competitive trait anxiety. Perceptual Motor Skills. (2014) 119:66178. doi: 10.2466/30.PMS.119c27z0

70. Nicholls AR, Levy AR, Polman RC, Crust L. Mental toughness, coping self-efficacy, and coping effectiveness among athletes. Int J Sport Psychol. (2011) 42:513-24. Available online at: https://psycnet.apa.org/record/201203633-001

71. Marchant DC, Polman RC, Clough PJ, Jackson JG, Levy AR, Nicholls AR. Mental toughness: Managerial and age differences. J Manage Psychol. (2009) 24, 428-437. doi: 10.1108/02683940910959753

72. Sheard M, Golby J. Effect of a psychological skills training program on swimming performance and positive psychological development. Int J Sport Exercise Psychol. (2006) 4:149-69. doi: 10.1080/1612197X.2006. 9671790

73. Gucciardi DF, Gordon S, Dimmock JA. Evaluation of a mental toughness training program for youth-aged Australian footballers: II. J Appl Sport Psychol. (2009) 21:324-39. doi: 10.1080/10413200903026074

74. Thelwell RC, Greenlees IA, Weston NJ. Using psychological skills training to develop soccer performance. J Appl Sport Psychol. (2006) 18:25470. doi: 10.1080/10413200600830323

75. Lee J. Mental health effects of school closures during COVID-19. Lancet Child Adolesc Health. (2020) 4:421. doi: 10.1016/S2352-4642(20) 30109-7

Conflict of Interest: The authors declare that the research was conducted in the absence of any commercial or financial relationships that could be construed as a potential conflict of interest.

Copyright (c) 2021 Mojtahedi, Dagnall, Denovan, Clough, Hull, Canning, Lilley and Papageorgiou. This is an open-access article distributed under the terms of the Creative Commons Attribution License (CC BY). The use, distribution or reproduction in other forums is permitted, provided the original author(s) and the copyright owner(s) are credited and that the original publication in this journal is cited, in accordance with accepted academic practice. No use, distribution or reproduction is permitted which does not comply with these terms. 